UJBM, Vol. 2, No. 2, July - December 2003, pp 29-37

ISSN 0975-3311

https:/ / doi.org/ 10.12725/ ujbm.3.4

\title{
WORK CULTURE IN INDIAN ORGANIZATIONS
}

A Journey Towards Organizations of Today's Knowledge Based
Industries Deep Kapoor*

\section{Introduction}

Work is a source of sustenance to human beings. The environment where the person works has a lot of effect on the efficiency and effectiveness. In a layman's language we can call this environment along with the processes working in it as the 'Work Culture'.

With the opening up of Indian economy and the flourishing of knowledge based industries in India, this environment of work has considerably changed and it has a marked influence on the social lives of the people working in these kinds of industries. As these industries are located mostly in big/metropolitan cities and affects educated urban middle/upper class generally, this paper will be somewhat skewed towards these class of people working mostly in large organizations. I will also concentrate on defining work culture, on types of work culture, on the impact of society on work culture, on emerging work culture and finally focussing on the knowledge based industries.

${ }^{*}$ Consultant, MindTree Consulting Pvt. Ltd., Bangalore 


\section{What is Work Culture}

Work culture refers to work related activities and the meanings attached to such activities in the framework of norms and values regarding work. These activities, norms and values are generally (but not always) contextualized in an organization. An organization has its boundaries, goals and objectives, technology, managerial practices, material and human resources as well as constraints (which is referred to as organizational culture). Its employees have skills, knowledge, needs, expectations and behavior. These two sets of factors - organizational and organismic interact and over the time establish roles, norms, and values pertaining to work. It is this totality of the various levels of interacting forces around the focal concern for work, which is labeled as work culture. The work culture also has its roots from the socio-cultural values and systemic features of the surrounding milieu.

\section{Kinds of Work Culture}

Work and organizational cultures are subsets of the larger societal culture. While each organization has its own work culture, two patterns are distinct: soft and synergetic, representing the extremes of a broadly conceived continuum of work. Soft work culture means that everybody in the organization is complacent enough and the motivation level of the employees to do something new is very less. The soft culture is not a desirable state of an organization in the synergetic work culture, socio-cultural values are utilized to mobilize and motivate manpower.

If organizational culture is conducive to excellence at work, high productivity, the centrality of work in employees' life space and a high quality of work life, the organization is said to have a work-conducive culture otherwise a non-work culture.

If an organization enforces strong work norms, maintains strict work disciplines and makes profits, but neglects and exploits its human resources the organization is said to possess an amoral work-centric culture. The employees lack involvement, commitment and desire to do something innovative in this kind of culture.

Similarly if an organization neglects the social needs of its employees in achieving technological excellence, it is said to be working under technocratic culture.

The criteria which determines the centrality of work for an individual are job affect and job clarity, time to devote to work i.e. work pressure, job and life satisfaction, value addition from the job, peace of mind, working conditions, up-to-date technology, superior-subordinate relationship, reinforcement (reward for hard work), status/prestige associated with the position/designation, extent of responsibility and freedom for making decisions, security of job and last but not the least money. 
Work culture changes with the organization's core activity. The work culture present in heavy industries is significantly different from that existing in diverse industries like banking, fashion, entertainment and knowledge based industries.

\section{Impact of Society on Work Culture}

Irrespective of organizational setting, the employees may tend to work hard, feel positive towards working and consider work to be central to their identity depending on their geographical or cultural region. A very clear example is the Japanese culture that socializes its members in cultivating a work-centric culture. The Indian cultural milieu is collectivist. Hence any culture in the organization should give due consideration to the group activities to a certain extent for success.

The social hierarchy existing in India makes Indians feel comfortable in the superiorsubordinate framework. Once a hierarchy is established the juniors goes to any extent to please their seniors. Hierarchical relationships are maintained by taking care of those who are inferior and maintaining deference and respectful compliance to superiors. The hierarchical groups in India are very supportive and inter-dependent and this is what is termed as 'vertical solidarity'. In India. it's the family, which is the most dominant ingroup. Even in work related matters it's the family that a person seeks advice from. Decisions are generally made in a group and this results in Indians becoming more dependent and seeking attention, advice, support and help even in situations where they can handle it all alone. It is the family values and principles only which a person tries to extend to the organization where he/she is working.

Conflict and cooperation seem to coexist in the Indian society and in Indian organization as well. In India, people give more preference to personalized relationship over contractual relationship. The formation of too many ingroups out of this personalized relationship can lead to factionalism and power play and can prove to be detrimental to the organization. The preference for harmony and tolerance as taught by an individual's religion helps maintain solidarity in an ingroup.

Because of very high rate of unemployment and low rate of spatial mobility in India, people seem to be complacent enough in their present jobs. Indian employees also seek high power needs. The factors like people's aspirations to build a strong nation and catch up with the West in material affluence and inroads made by the Western values have proved to be helpful as well as harmful to the work culture in different organizations. 


\section{Brief Overview of Emergence and Changing of Work Culture in Indian Organizations}

The British were the first to introduce the western type of public administration in India. The organizational structure, administrative procedures and work methods were all patterned after the British organization. The culfural preference for relationship orientation, which requires a superior to be nurturant and the subordinate to be dependent was never totally erased from the Indian psyche. The rapid expansion of industrial activities required a large-scale import of Western technology and work forms which were expected to contain Western work values. The work organizations were put into the service of national development with the twin goals of growth and social justice. The developmental roles were not congruent to economic objectives. The climate in many of the work organizations is still marked by bureaucratization, impersonalization, political interference, and the ethos of a welfare organization (more in public sector than in the private sector). With the recruitment of employees from broader spectrum of the society there has been greater penetration of social habits and cultural values into the fabric of the work organization.

The emphasis on equitable distribution of wealth had its roots in the Indian cultural preference for harmony and sharing of wealth. In the highly heterogeneous and pluralistic social context of India, the condition of the employees was sought to be improved through building tolerant organizations with minimal conflict. But it worked other way as employees construed these employee friendly policies to meet their personal and social obligations while neglecting work requirements.

\section{Indian Organizations of Today}

The Indian organizations of today fend to possess a blend of Western and Japanese corporate philosophy and show a strong orientation towards Indian cultural milieu and traditions at the same time. The Japanese philosophy of social interaction and giving a lot of consideration to human values at the organizational level has also driven Indian growing organizations to strive for an open work culture. Sinilarly as per Western philosophy, individualism also exists to a certain extent in every organization but the Indian mindset always gives it a backseat when it comes to clashes between the two interests within a group. Privatization has changed the power distribution equations completely. For the organizations to remain competitive in the increasingly globalized market, it has become imperative for the Indian organizations to make strategy for an effective work culture that can motivate the employees to give their best and for achieving technological excellence. Innovative management practices combined with nurturance of the employees, so that the 
latter can grow, assume a learning mode, and take on the responsibility of keeping the industries competitive. The 'knowledge based industries', the new economy drivers, can be considered for perfectly qualifying this definition.

Performance based promotion system has become the hallmark of the organizations in these industries. Appropriate reinforcement systems have been developed for rewarding better performance and punishing work shirking behaviors.

Corruption, which has totally damaged the work culture in many of the Public sector units, Government organizations and in some private organizations, has lost its relevance in these kind of industries because of more transparency and accountability. The de-centralization of decision-making process has made the employees more accountable for whatever they do. This has inculcated more responsibility in the work force and is helping them in taking quick and right decisions in their personal lives also. The culture symbolizes more of competition where to be professional is to be strongly influenced by western norms of personal growth, personal efficiency, pioneering innovative motive etc. The nature of work imposes so much stress on the employees that they need to resort to psycho-spiritual values. It is in this context that yoga, meditation and breath-control have become a part of the work culture to relieve employee's stress to get maximum productivity. A myriad of cultural activities are organized at quite frequent intervals so that the families of the employees can interact and the activities can also act as stress relievers.

Leaders need not be managers in these organizations. Any person who is capable enough can emerge as a leader to do something innovative. It is the leader only who highlight the mission, concretize it into clear objectives and evolve systems to realize them. The leader is a role model who initiates, guides, directs and inspires the subordinates.

These industries depict a unique culture of not having any Trade Unions unlike the other manufacturing and services industries. The Trade Unions had always proved to be the best medium to redress the problems of the employees. But in these industries employees need to sort out their problems through direct interaction with their immediate superior. Indian managers are stressing on open-door policy that allows any employee to approach him directly for redressal. The employee should get the feeling that 'the company cares'.

English as a language is gradually becoming the mode of communication among the employees in these kinds of organizations although regionalism to some extent comes when people start talking in their own language once they are together. It's now Emotional Quotient (EQ) and Spiritual Quotient (SQ) of an employee along with the Intelligent Quotient $(I Q)$ determines the success of an employee in the 
organization. An awareness of the concomitant impact on the physical environment of the workplace is also becoming more widespread. The social and the physical environments are changing concurrently and systematically. The employees should have a sense of belongingness to the organization so that they start looking towards a broader picture of organization's goals and keep their selfish interests to the lowest level. The spirit of equality and camaraderie is strengthened with the top management, managers and workers taking food in the same canteen.

The newly modeled Indian organizations of today are the live examples of competition thriving along with co-operation in all professional and social activities. Benchmarking has made these organizations to strive for excellence. The quality of work existing in these modern organizations of today demands a lot of interaction among the group members and long hours of working in a team. The social bond that people develop out of this close interaction and personal touch crosses all the barriers encompassing cultural, regional, social background and caste aspects.

\section{Knowledge based Industries}

The work culture in these industries covers almost all the aspects mentioned for the work culture existing in the organizations of today. It's the 'Work Centric Nurturant Culture' definition that qualifies for these industries. These industries characterizes the restructuring of work that is taking place in relation to the shift from brawn power to brain power, and away from the mass production of products to the application of ideas.

Human resources are the most important asset of these industries. To retain the best talent in the industry, the organizations in these industries are spending a lot in terms of giving the employees the best facilities, the best incentives and the best remuneration. The rewards are directly related to the performance of the employee in the organization. In terms of incentives, the firms have come up with the concept of Employee Stock Option Plans (ESOPs), which has become a buzzword today. ESOP is an effective mean to give sense of ownership to the employees. Flexible timing is another mantra espoused by these organizations to give full freedom to the employees to work af timings convenient to them. These organizations stress a lot on innovation and flexibility, which is directly related to the job satisfaction of the employees.

The organizations also espouse the philosophy of 'Corporate Governance' where the company's most important responsibility is to maximize the shareholder's value by becoming'more disciplined and ethical. This demands more accountability and transparency on the part of management that needs to be permeated to the grassroots level of the organizational culture. 


\begin{abstract}
A lot of stress is given to learnability of the employees and that's why the organizations stress a lot on training activities of the employees. Hence a lot of stress is given on knowledge sharing among the employees. It's not only the technical skill of the employee that needs to be continuously updated but also the inter-personal skills that needs to be refined at regular intervals. The employees in these industries are frequently sent abroad to the client side where they represent the organization visà-vis its work culture. Loyalty to an organization has become outdated with the culture of job-hopping pervading almost every organization. In organizations where employees remain hooked to their desks and social interaction is very less, there are a number of activities and parties organized by the organization where the employees can mix up easily and share their thoughts. In nutshell, the organizations in these industries offer fun work environment with plenty of professional freedom and high levels of responsibility.
\end{abstract}

\title{
Some Recent Policies in Organizations affecting Work Culture
}

There is always a policy change taking place in the organization for achieving the goals of the organization like many organizations have introduced Voluntary Retirement Scheme (VRS) to downsize (reduce the employee strength) to reduce costs. This is applicable to mostly ailing Public sector units and private organizations in the brick and mortar sector. I am not elaborating on this policy as it is hardly observed in the organizations of new economy.

The organizations have come up with an 'Anti-Sexual Harassment Policy' as an initiative to prevent any abuse against the women workforce. This is one of the policy that reflects the Changing Status of Women in the Workplace of the new economy.

The increasing fluidity of organizational structures and cultures has opened up opportunities for women who are well informed, well placed and well organized. This trend is more visible in the urban class with rural female population still lagging quite behind. In certain cases the working women have proved themselves to be more productive than their male counterparts. The work environment has become so liberal that even women are staying late in the nights to complete their work. They are interacting continuously with the male colleagues and discussing with them their family and other problems. They attend all official parties and functions, which continue sometimes even late into the night. The noticeable point is that they are still maintaining the traditional and moral values of the society. 


\section{Impact of Work Culture on the Society and Its Members}

With the skyrocketing salaries of the skilled work force in the new economy industries, consumerism has become quite evident in the metropolitan cities. Life is becoming more modernized in megalopolis. The mind-boggling salaries and incentives offered by these organizations is in line with their philosophy to create and share wealth. Decision-making capability in the social life of an individual has improved drastically with the decentralization of decision-making process in the organizations. Similarly, leadership role in the organization can teach a person to fight against any social injustice in the personal life. The win-win climate in these organizations can foster positive attitude in the employees that helps them in being successful in the social life. These claims can be substantiated by the awareness of the working people living in big cities about the problems faced by the society and their willingness to take an initiative to clean the malaise faced by the society.

Society is getting benefited by the new breed of entrepreneurs coming up. The spirit of competition tends to permeate even in the social life with people vying with each other for leading a more luxurious life.

The society as a whole is becoming more cosmopolitan in big cities with the people from different parts of the country living together and sharing each others cultural values and traditions. A typical example is Bangalore where software engineers working in the Silicon Valley of India have formed their own family by concentrating themselves in three or four areas of the city like Koramangala, Jayanagar, and BTM etc.

The success of women in the economic front has changed the mindset of the people towards a girl child. Now women have become more independent and are having an equal say in the household matters. But the joint family system is gradually disintegrating as most of the organizations of new economy are located in big cities and hence persons from towns and small cities have to move out and stay away from their family.

The work culture in these organizations also emphasize on inculcating, in their employees, a concern for the society. They can sense the problems existing in the society and try to contribute whatever is possible from their side. 


\section{Conclusion}

Work Centric Nurturant Culture, the culture existing in most of the organizations of today, integrates the technological and social orders to realize high produclivity as well as meet the needs and expectations of employees. A blend of qualityconsciousness and nurturance will enable the front-runners of industry to remain competitive as well as culturally integrated. The work culture is not something static, it keeps on changing with the change in the vision of the organization, change in the needs of people and last but not the least change in the need of the society. 